\title{
A IDEIA DE ESPAÇO NO TRATADO DA NATUREZA HUMANA, DE HUME ${ }^{1}$
}

Andrea Gachel (UEL) ${ }^{2}$

andrelmg@hotmail.com

Resumo: $\mathrm{O}$ artigo pretende analisar a discussão feita pela filosofia humeana acerca da ideia de espaço, a partir da sua rejeição da tese da divisibilidade infinita da extensão e da sua defesa do atomismo perceptivo. Nesse sentido, o texto parte da abordagem do contexto de análise no qual Hume está inserido: o debate entre as filosofias de Locke e Berkeley quanto à abstração da extensão. Procura-se apontar que a análise de Hume sustenta a existência dos pontos matemáticos e mostrar em que medida a concepção relacional do espaço é a forma humeana de buscar a mediação entre seu atomismo perceptivo e o abstracionismo.

Palavras-chave: Espaço; imagismo; empirismo.

\section{INTRODUÇÃO: OS PRESSUPOSTOS DA DISGUSSÃO EM LOCKE E BERKELEY}

A abordagem de Hume, a respeito do espaço, está inserida num contexto maior de discussões correntes na ciência e filosofia dos séculos XVII e XVIII, do que se seguiria que, a fim de que se pudesse compreender a totalidade das questões envolvidas no problema do espaço neste autor, tivéssemos que traçar um inventário mais completo dessas influências. No entanto, pensamos poder ao menos iniciar

\footnotetext{
${ }^{1}$ Recebido: 26-04-2016/ Aceito: 03-08-2016/ Publicado on-line: 31-07-2017.

2 Andrea Cachel Professora Adjunta da Universidade Estadual de Londrina, Londrina, PR, Brasil.
} 
um debate mais específico referente a grande parte dos assuntos expostos partindo de dois autores fundamentais do período: Locke e Berkeley ${ }^{3}$. Isso porque já é célebre a importância deste último na filosofia de Hume e, mais especificamente, porque parece ser inegável a semelhança da estruturação da questão no Tratado e nos Princípios. Assim, perceber, ao menos brevemente, o estatuto da filosofia berkeleyana acerca do espaço é um meio eficaz de entender o que está em jogo, nesse tocante, na filosofia humeana. Da mesma forma, considerando que um dos alvos principais dos Princípios é Locke e que Berkeley, sobretudo, visa apresentar críticas à abstração do espaço, realizada por esse autor, parece interessante iniciar a discussão com o Ensaio, tentando ver no mesmo alguns pressupostos centrais do problema.

Em Locke, as questões pertinentes ao espaço estão centralizadas na discussão acerca da diferença entre espaço e corpo, portanto, na necessidade de afirmar uma distinção real entre estas ideias. Será fundamental, para este autor, mostrar que espaço e corpo são ideias distintas, nisso apresentando uma crítica direta às filosofias de cunho cartesiano. Fundamentalmente, o Ensaio irá mostrar que a ideia de espaço é abstrata, o que permitirá, ademais, que possa ser considerada divisível infinitamente, ainda que a matéria e a percepção tenham que ser limitadas por um ponto, no caso sensível.

Através da discussão com os cartesianos, Locke procura defender uma independência da noção de espaço com relação às qualidades sensíveis, por intermédio das quais sua

\footnotetext{
${ }^{3}$ Para uma análise das influências de Hutcheson e Bayle na abordagem humeana da noção de espaço, ver KEMP SMITH (1964, p. 279-290 e p. 325-338).
} 
ideia é originada, aspecto no qual Berkeley irá alicerçar sua crítica e que também será alvo da censura humeana. A estratégia lockeana, nesse sentido, parte da tentativa de mostrar que compreender que espaço e corpo são ideias equivalentes é confundir solidez e espaço:

A ideia de solidez é recebida por nós pelo tato e é deriva da resistência que percebemos no corpo, quando qualquer outro corpo tenta ocupar o seu espaço, antes que ele o desocupe. Não há nenhuma Ideia que nós recebemos mais constantemente da sensação que a Solidez. Se nos movemos, ou repousamos, seja qual for a postura em que estejamos, sempre sentimos alguma coisa abaixo de nós, que nos suporta e sustenta, impedindo nossa queda. E os Corpos que tocamos diariamente nos fazem perceber que, enquanto eles permanecem entre nossas mãos, impedem a aproximação delas por meio de uma força indestrutível (LOCKE, 1975, p. 122-3).

Segundo Locke, os cartesianos definem corpo como algo sólido e extenso, mas embora a solidez não exista sem espaço, ambas as ideias são consideradas distintas. Isso porque, para o autor, embora o espaço seja uma ideia simples que é recebida por meio da visão e do tato, não se poderia confundir a extensão e as qualidades sensíveis e táteis que sempre lhe acompanham. Se, de fato, não é possível ver ou tocar um objeto sem receber a impressão de extensão ou espaço ${ }^{4}$, isso não significaria haver uma dependência entre as ideias.

Estabelecida para Locke a independência da ideia de espaço, com relação ao corpo ou à matéria, algumas consequências se seguirão, consequências essas que serão um problema crucial para Berkeley e Hume e que consistirão, por exemplo, na possibilidade da divisibilidade infinita des-

\footnotetext{
${ }^{4}$ Tanto Locke, como Berkeley e Hume utilizam indistintamente as palavras espaço e extensão. Locke apenas especifica o sentido de extensão para diferenciá-la de expansão, quando estiver falando da ideia abstrata de espaço.
} 
ta ideia. Dessa abordagem decorre a compreensão de que o espaço é uma ideia simples, recebida diretamente pelos sentidos. Ainda que distinta da ideia de corpo ou matéria a que estaria anexada, a ideia de espaço é, para Locke, imediatamente percebida pelos sentidos. Conforme o texto do Ensaio, independente do modo como consideremos o espaço, seja como a relação entre as partes de um corpo, seja com relação à distância entre as extremidades entre diferentes corpos, é sempre a mesma ideia simples de espaço que está em foco. A ideia de espaço seria originada por meio dos objetos com os quais os sentidos se ocupam, mas uma vez fixada essa ideia no espírito, poder-se-ia repeti-la, relembrá-la e recombiná-la. A ideia abstrata de espaço não se confunde com a extensão particular por meio da qual teve origem, tanto que será preciso diferenciar extensão e expansão: "o espaço tem expansão e o corpo tem extensão. Expansão é a ideia abstrata e simples de espaço" (LOCKE, 1975, p. 180). A expansão, portanto a ideia abstrata, não é limitada pela matéria, de modo que poderá ser repetida ao infinito. A ideia abstrata de espaço pode ultrapassar a sua existência particular e estender seus limites. Da mesma forma, tomada como abstrata, ela pode ser dividida ao infinito, pois qualquer divisão, qualquer parte, será ainda ideia simples e abstrata de espaço. Apenas fixaríamos, segundo Locke, uma parte limite, da qual podemos ter uma ideia clara e distinta, no caso do espaço, o ponto sensível.

O infinito, para Locke, é uma modificação do espaço, assim como do tempo. Juntando partes determinadas do espaço, chegamos à ideia da infinitude do espaço. Mas, isso não significa dizer que há atualmente um espaço infinito, ou seja, não é possível ter ideia clara de um espaço infinito. O mesmo ocorre com a divisibilidade infinita. É possível ter 
ideia da divisibilidade infinita do espaço, mas isso não implica a concepção direta da ideia de um espaço infinitamente pequeno. Trata-se de uma divisibilidade numérica, uma divisão semelhante à divisão da unidade em frações. Assim, a consequência da separação, no Ensaio, entre a ideia de espaço tomada como uma ideia abstrata e o corpo extenso por meio do qual ela é originada será que, embora não seja possível possuir uma ideia clara de um espaço infinitamente grande ou pequeno e que haja um limite no ponto sensível, poder-se-á dividir a ideia abstrata de espaço por meio de uma relação numérica entre as partes limites de que se constituirá um espaço somado ao infinito ou fracionado ao infinito. A abstração permite a Locke não encontrar paradoxo nesse fato, o que não ocorrerá em Berkeley, no que será seguido por Hume.

Ademais, a independência entre a ideia de espaço e a de corpo poderia ser comprovada pela necessidade de afirmarmos ao menos a existência da ideia de vácuo. Inicialmente Locke sustenta o vácuo com base um argumento que apela para a onipotência divina:

Mais do que isso, aqueles que afirmam a impossibilidade do Espaço existir sem a Matéria precisam não apenas pressupor que o corpo é infinito, mas também negar que Deus possa aniquilar qualquer parte da matéria. Ninguém, eu suponho, negaria que Deus pode colocar um fim a qualquer movimento da matéria e deixar todos os corpos do Universo em repouso e fazê-los ficar assim por quanto tempo quiser. Todo aquele que admitir que Deus pode, durante esse repouso, aniquilar tanto este livro como o corpo de quem o está lendo deve admitir a possiblidade de um Vácuo. Porque é evidente que o Espaço, que era preenchido pelas partes do corpo aniquilado, permanece e consiste em um Espaço sem Corpo (LOCKE, 1975,p. 176).

Na sequência, argumenta que a possibilidade do movimento implica a existência de um espaço vazio: 
E nem precisamos ir tão longe e falarmos das últimas partes dos corpos no Universo ou da onipotência de Deus para sustentarmos o Vácuo. O movimento dos corpos que estão ao nosso redor pareceme uma evidência do mesmo. Porque gostaria que alguém tentasse dividir um corpo sólido de qualquer dimensão que escolha e tornasse possível que as partes sólidas se movam livremente para cima e para baixo se não houver um espaço vazio ao menos do mesmo tamanho que a menor parte em que foi dividido o suposto corpo sólido (LOCKE, 1975, p. 177).

O ponto fundamental da crítica de Berkeley a esse tipo de exposição será, então, como já mencionamos, a teoria da abstração. Para ele é porque o espaço é tomado como uma ideia abstrata que alguns paradoxos, dentre os quais o da divisibilidade infinita da ideia de espaço, poderão surgir. Tendo em vista principalmente que um dos fundamentos de sua filosofia é a consideração de que o que existe, existe apenas enquanto ideia, Berkeley não poderá admitir, por um lado, a abstração de uma ideia da sua percepção, e, por outro lado, que se possa propor uma divisibilidade infinita incompatível com a necessidade de haver um mínimo sensível, ou seja, que haja dois níveis naquilo que é, no final das contas, apenas ideia.

A ideia de espaço tal como pensada na filosofia de Locke seria, segundo as críticas berkeleyanas, uma tentativa não só de abstrair a extensão das outras qualidades, mas também de abstrair a extensão de sua percepção, o que seria absurdo levando-se em consideração a defesa berkeleyana de que ideias devem ser sempre percebidas. Se a extensão ou espaço depende da cor, que é uma sensação, com existência meramente na percepção, não haveria como abstrair espaço da sua própria percepção. Não seria possível considerar o espaço em si mesmo e achar que ele pode ser separado das qualidades que o acompanham e da 
percepção dessas qualidades. Na medida em que a origem da ideia de espaço estaria ligada aos objetos sensíveis, que se reduziriam apenas em sensações, portanto em ato perceptivo, o espaço não poderia subsistir sem a percepção:

Mas, antes de começar a discutir mais particularmente esse assunto, penso que é apropriado considerar a extensão de maneira abstrata, pois sobre isso se fala muito, e eu tendo a pensar que, quando os homens falam da extensão como sendo uma ideia comum dos dois sentidos, supõem secretamente que podemos isolar a extensão de todas as outras qualidades tangíveis e visíveis e obter dela uma ideia abstrata que afirmam ser comum tanto à vista quanto ao tato. Devemos, portanto, entender por extensão em abstrato um ideia de extensão - por exemplo, uma linha ou superfície - inteiramente despojada de todas as outras qualidades sensíveis e circunstâncias que pudessem determiná-la enquanto uma existência particular qualquer: ela não é nem preta nem branca nem vermelha, nem tem alguma cor ou qualidade tátil; e, consequentemente, não tem nenhuma magnitude finita determinada, já que o que limita ou distingue uma extensão de outra é alguma qualidade ou circunstância em que diferem (BERKELEY, 2010, p. 220).

Berkeley ressalta (2010, p. 133) que a vista não percebe a distância, nem imediatamente, nem por meio de linhas e ângulos; esta é apenas sugerida pela visão tendo em vista uma conexão aprendida na experiência entre visão e tato. Além disso, como parece acontecer em Locke (1975, p. 212), para Berkeley é pela adição de partes que se chega a uma extensão infinita. Assim, provar a impossibilidade da divisibilidade infinita do espaço passará pela evidência de que uma extensão finita não pode possuir infinitos números de partes, ou seja, mostrando que ser infinitamente divisível é possuir número infinito de partes, mesmo método utilizado por Hume, como veremos na próxima seção. A refutação da hipótese de divisibilidade infinita de uma extensão finita envolverá o pressuposto de que uma extensão 
finita particular (ou seja, não abstrata) só pode ser pensada como algo existente apenas no espírito, portanto enquanto ideia. Sendo esta extensão apenas uma ideia, é necessário que cada parte dessa mesma extensão possa ser percebida pelo espírito. Berkeley estabelece (1998, p. 112) que a hipótese da infinita divisibilidade da matéria se contrapõe ao princípio ser é ser percebido. Isso porque essa teoria, segundo ele amplamente aceita, pressupõe que a extensão seria finita apenas porque os sentidos não percebem as partes diminutas e não porque elas não existam. Com os sentidos mais agudos, eles perceberiam um maior número de partes. Todo objeto seria infinitamente extenso e, portanto, sem forma e figura, do que decorre que é só na medida em que são percebidos que eles existem enquanto corpos particulares. O corpo não se alterou, mas tão somente a sua percepção. Portanto, a existência particular dos corpos seria diretamente relacionada com essa percepção. E o que esses teóricos chamam de infinidade de partes, em realidade, apenas representaria a percepção contínua de novas partes, as quais precisam ser determinadas qualitativamente.

Hume, em grande medida, desenvolverá as considerações sobre o espaço de modo muito semelhante a Berkeley, também estruturando a questão em dois eixos principais, a saber, as discussões acerca da divisibilidade infinita e a respeito da origem da ideia de extensão. Suas análises partirão da rejeição à possibilidade de se dividir infinitamente uma extensão finita, primeiro como ideia e depois passando ao espaço considerado nele mesmo, resultando essa recusa na defesa dos pontos matemáticos, esse sendo um ponto bastante peculiar de sua teoria. A recusa da abstração do espaço e o atomismo perceptivo estarão vinculados, tornandose indispensável, portanto, a compreensão desses aspectos, 
o que faremos nas próximas seções. Será fundamental, nesse contexto, o entendimento de que a qualificação humeana da ideia de espaço como uma relação entre pontos sólidos e tangíveis representa uma tentativa de conciliação entre seu atomismo e o seu modo de compreender o abstracionismo.

\section{A NEGAÇÃO HUMEANA DA DIVISIBILIDADE INFINITA DA IDEIA DE ESPAÇO E A DEFESA DOS PONTOS MATEMÁTICOS}

O primeiro momento da argumentação humeana contra a divisibilidade infinita do espaço consiste na consideração acerca dessa impossibilidade com relação ao espaço tomado apenas enquanto ideia. Para tanto, o pressuposto inicial tomado pela filosofia humeana é a finitude da mente humana, princípio esse que afirma ser corrente na filosofia da época ${ }^{5}$. A mente não seria capaz de formar uma noção adequada do infinito, ou seja, não poderia ter uma ideia atual de infinito. $\mathrm{O}$ segundo pressuposto que assume terá como consequência uma rejeição também da noção de infinito potencial. Isso porque, para Hume, seria evidente que o que é divisível infinitamente deve possuir um número infinito de partes e que estabelecer um limite para o número de partes é estabelecer um limite para a própria divisão. Assim, uma mente finita implica não só que não se possa possuir ideia de um número infinito de partes, mas também

\footnotetext{
${ }^{5}$ NEWMAN (1981, p. 4-6) destaca que Hume se reporta nesse caso à discussão da distinção aristotélica entre infinito atual e potencial e à recusa de que a mente finita possa compreender o infinito real, portanto, seja capaz de formar uma ideia adequada do mesmo. FRASCA-SPADA (1998, p. 21-22) afirma que Hume assume um pressuposto da filosofia cartesiana, dando a ele um direcionamento bem diverso ao dado por aquela, ou seja, não o utilizando para demonstrar a certeza e imediticidade da ideia de infinito, mas para problematizar a origem de tal ideia na experiência.
} 
que não se possa dividir infinitamente ${ }^{6}$ :

Ao rejeitar a capacidade infinita da mente, supomos que podemos chegar a um fim na divisão de suas ideias; não existe qualquer meio possível de fugir da evidência dessa conclusão (HUME 2000, p. 23).

Em Hume, tomar essa evidência, ademais, será aceitar o mínimo sensível. Ou seja, significará que tanto ideia como impressão devem encontrar um limite, chegar a um mínimo, a partir do qual não pode haver divisão sem aniquilação, o que o autor comprova partindo de dois exemplos, o primeiro dos quais diz respeito à composição que podemos fazer para formar a ideia de um corpo. A capacidade finita da mente implica que deva haver um limite na divisão das mesmas. Ainda que se tenha, por exemplo, uma ideia distinta do número e das proporções da milésima ou da décima parte do grão de areia, a imagem pela qual o grão de areia é representado é a mesma pela qual a sua milésima parte o é, não podendo haver diminuição da primeira. Embora um grão de areia seja proporcionalmente maior que a sua divisão, as ideias de grão de areia e a da milésima parte de um grão de areia não podem se diferir, justamente porque a milésima parte é menor que o mínimo sensível.

Num segundo exemplo, o texto procura mostrar que o mesmo valerá para as impressões. Hume afirma que também com relação às impressões dos sentidos há um limite, o qual não comporta divisões, sem que haja aniquilação:

Coloque um ponto de tinta sobre um papel, fixe seu olho sobre esse ponto, retire-se para uma distância tal que, finalmente, você o perca

\footnotetext{
${ }^{6}$ Nesse ponto, como vimos, Hume parece acompanhar Locke e Berkeley. KEMP SMITH sugere que Bayle é a fonte comum a esses autores e que é de sua filosofia que deriva o pressuposto de que a divisão infinita da matéria implica um número infinito de partes, do que se seguiria a exigência de um infinito atual e real e não potencial. Mas Hume não acompanharia a rejeição de Bayle aos pontos matemáticos (1964, p. 325-330).
} 
de vista. É evidente que, no momento antes de desaparecer, a imagem ou impressão era perfeitamente indivisível. Não é por falta de raios de luz que atinjam nossos olhos que as partes diminutas dos corpos distantes não transmitem qualquer impressão sensível, mas porque eles foram colocados além da distância na qual sua impressão foi reduzida a um minimum e era incapaz de qualquer diminuição adicional (HUME, 2000, p. 24).

Nesse caso, o autor se remete ao mínimo perceptivo, mostrando que não é possível haver a própria percepção sensível, para além de um limite. No caso da mancha de tinta, a última impressão sensível era totalmente indivisível, ou seja, não seria possível perceber algo menor que a mesma. Assim, a descoberta de partes menores que aquelas referentes ao mínimo sensível torna necessária uma tarefa de composição dessas partes e de determinação de suas proporções (HUME, 2000, p. 25). Não podemos dividir infinitamente a nossa percepção, ou seja, assim como para as ideias, há um limite para a impressão. A defesa de um mínimo perceptível, portanto, aplica-se tanto às ideias como às impressões. E a composição de um objeto a partir da percepção de suas partes é, em realidade, apenas uma divisão no mesmo objeto já concebido. Tanto as partes diminutas quanto o objeto extremamente pequeno estão no limite da percepção e a composição do objeto pequeno a partir de partes que, do ponto de vista da sua percepção se assemelham a ele, trata-se simplesmente da composição de uma ideia na qual se estabelece uma proporcionalidade pressuposta pela razão e não diretamente pelos sentidos.

Partindo da demonstração de que a ideia de espaço não é infinitamente divisível, conjuntamente com a explicação de como as ideias representam as partes mais diminutas da extensão, explicação essa que é bastante complexa, Hume pretenderá dar um passo além. Da consideração de que as 
ideias representam adequadamente todas as partes da extensão, o autor irá mostrar que a extensão, nela mesma, não pode ser dividida infinitamente:

Quando ideias são representações adequadas dos objetos, as relações, contradições e acordos entre elas são totalmente aplicáveis aos objetos. E podemos observar, em geral, que essa é a base de todo o conhecimento humano. Nossas ideias são representações adequadas das menores partes da extensão; assim qualquer divisão e subdivisão que possamos supor aplicadas a essas partes não podem ser inferiores a algumas ideias que formamos. A consequência evidente disso é que tudo o que parece impossível e contraditório na comparação dessas ideias deve ser realmente impossível e contraditório, sem qualquer desculpa ou escapatória (HUME, 2000, p. 24).

A representação adequada de todas as partes da extensão, como dissemos, é, então, fundamental. A adequação, no entanto, é compreendida como circunscrita ao mínimo sensível, ou seja, se chegamos à milésima parte de algo por várias divisões (feitas, ao que parece, pela razão, e não pelos sentidos), isso não faz com que essa parte seja inferior àquelas ideias indivisíveis que possuímos em nossa percepção. Do fato de que nenhuma parte é inferior ao mínimo se seguirá que da contradição e impossibilidade das ideias possa-se chegar à impossibilidade e contradição de fato. Assim, para Hume, se for possível evidenciar a contradição da divisibilidade infinita da ideia de uma extensão finita, poder-se-á estabelecer que em realidade uma extensão finita não pode ser dividida infinitamente ${ }^{7}$.

\footnotetext{
${ }^{7}$ FRASCA-SPADA (1998, p. 46-55) analisa as implicações ontológicas da defesa humeana de um mínimo perceptivo. Quando discute a noção de existência externa, Hume afirma que não podemos conceber adequadamente objetos externos enquanto existências especificamente diferentes das percepções. E na sua análise acerca da crença no mundo exterior, afirma que a pressuposição de que nossas percepções são os próprios objetos é natural e se sobrepõe à reflexão filosófica que defende uma dupla existência, a de percepções e a de objetos. Contudo, Hume deixa aberta a possibilidade de supormos que haja um mundo exterior especificamente diferente das percepções, ainda que reconheça a sua inconceptibilidade. Frasca-Spada argumenta que isso sigCont.
} 
Para o Tratado, como no Ensaio e nos Princípios, conforme já nos referimos, é pela adição de partes indivisíveis que se estabelece uma adição ao infinito e, em decorrência, é pela adição da ideia de partes indivisíveis que é possível aumentar a ideia da extensão. Conforme o autor, se a extensão finita for infinitamente divisível não pode ser contraditório supor que ela contém um número infinito de partes e se for contraditório supor que a extensão finita contém um número infinito de partes, nenhuma extensão finita pode ser infinitamente divisível. Mas, se possuir um número infinito de partes é a mesma coisa que ser uma extensão infinita, é absolutamente contraditório pensar que a extensão finita é infinitamente divisível.

É importante perceber que é pelo entendimento humeano de que há uma representação adequada que se pode passar da contradição da ideia de extensão finita infinitamente divisível para a sua impossibilidade real. Ou seja, e essa ponte é bastante questionável, a ideia atômica é correlata do ponto real de extensão. Tanto a defesa de um mínimo perceptivo e a possível correlação entre ele e uma qualidade real da extensão são centrais e explicam a não aceitação de Hume da objeção de que as partes divisíveis infinitamente poderiam ser proporcionais e não alíquotas. A objeção justamente seria no sentido de mostrar que par-

nifica que não é seguro transferir para os objetos externos aquilo que atribuímos às percepções, mas que tudo o que podemos imaginar quanto ao mundo exterior deve ser aplicável às percepções. Microscópios e telescópios, Hume mostraria, não descobrem novos mundos e sim novas perspectivas do mesmo mundo. Quando concebemos que haja partes menores que as que percebemos (e que poderiam ser percebidas por um microscópio, por exemplo) não subvertemos o princípio segundo o qual há um mínimo perceptivo concebível e que a divisão terá um limite. Esse limite da percepção implica que a própria realidade também precise ter um limite, a fim de que não imaginemos algo quanto ao mundo exterior que não possa ser aplicado às percepções. A percepção, contudo, não pode nos dar informações quanto a qual seja esse mínimo na realidade, mas tão somente nos obriga a inferir que ele existe e que a matéria não pode ser infinitamente divisível. 
tes proporcionais adicionadas não formam uma extensão infinita e, desse modo, seriam perfeitamente coerentes com a noção de extensão finita. A resposta de Hume leva em conta o princípio da indivisibilidade da ideia, entretanto, mais do que isso, parece oferecer um comprometimento entre essas ideias indivisíveis e a extensão propriamente dita:

Tem sido objetado a mim que a divisibilidade infinita supõe apenas um número infinito de partes proporcionais e não de partes alíquotas, e que um número infinito de partes proporcionais não forma uma extensão infinita. Mas esta distinção é inteiramente frívola. Sejam essas partes chamadas de alíquotas ou proporcionais, elas não podem ser inferiores àquelas partes minutas que nós concebemos; e, portanto, não podem formar uma extensão menor pela sua conjunção (HUME, 2000, p. 25).

A resposta parte de um princípio: essas partes proporcionais não poderiam ser menores que as ideias indivisíveis. $\mathrm{E}$ isso pareceria valer não apenas para a ideia de partes proporcionais da extensão, mas também para as próprias partes da extensão ${ }^{8}$. Partindo do atomismo perceptivo e estendendo-o às qualidades reais da extensão, ele procura evidenciar a possibilidade dos pontos matemáticos:

Esta é uma máxima estabelecida na metafísica: tudo o que a mente concebe claramente inclui a ideia de existência possível, ou, em outras palavras, nada do que imaginamos é absolutamente impossível. Nós podemos formar a ideia de uma montanha de ouro e disso concluir que tal montanha possa efetivamente existir. Mas não podemos

\footnotetext{
${ }^{8}$ NEWMAN (1981, p. 7-9) analisa que essa distinção é discutida por Bayle e diz respeito à diferença entre infinito real e potencial, tendo em vista que partes alíquotas pertencem a magnitudes consideradas discretas e as proporcionais a magnitudes contínuas. Uma defesa de partes proporcionais implicaria a possibilidade de uma divisão infinita em uma extensão finita, porquanto a divisão nesse caso é meramente potencial. Esse comentador argumenta que a recusa de Hume se deve ao atomismo peculiar de sua filosofia, o qual postula um limite para a imaginação e remete esse limite à extensão enquanto tal, conforme será exposto a seguir no artigo.
} 
formular uma ideia de montanha sem um vale, e, devemos, portanto, considerar que é impossível que uma tal montanha exista (HUME, 2000, p. 26).

A noção de que há existências menores que os mínimos perceptíveis derivaria de conclusões que podemos extrair da razão, sem que isso signifique, contudo, qualquer abstração quanto à sensibilidade. É esse o pressuposto humeano para defender a existência dos pontos matemáticos, no Tratado. Temos a ideia de extensão. Essa ideia não é infinitamente divisível, na medida em que a mente é limitada. Então há a ideia de uma extensão composta de partes indivisíveis e ela não é contraditória - portanto ela é possível. Mais do que isso, no Tratado fica claro que é porque os pontos matemáticos são possíveis que, definitivamente, a divisibilidade infinita da extensão é absurda (HUME, 2000, p. 26-7). Sendo possíveis os pontos matemáticos, não haveria como negar que a extensão finita encontra neles o seu limite 9 .

Todo esse modo de pensar a extensão resulta em consequências importantes para a forma como Hume qualifica a geometria, especialmente no Tratado. Para ele, as definições da geometria só são coerentes caso se admitam os pontos matemáticos: "Um sólido é limitado por uma superfície; a superfície é limitada pela linha; uma linha é limitada por um ponto; mas eu afirmo que, se as ideias de ponto, linha ou superfície não fossem indivisíveis, seria ab-

\footnotetext{
${ }^{9}$ BAXTER (1988) sintetiza de forma interessante o argumento humeano. Partes indivisíveis não seriam extensas, sendo assim, a menor coisa extensa seria algo composto no mínimo de duas partes inextensas e indivisíveis. Objetos compostos de partes existem apenas do ponto de vista linguístico, partindo-se do pressuposto de que a existência caberia apenas à unidade. Por isso, tudo que é extenso tem ao menos dois termos, os quais devem existir e ser separáveis. Ademais, a ideia "abstrata" de extensão é a maneira de aparição dos pontos, o que pressupõe que toda extensão deve ser composta de partes, as quais ocupam o espaço. Apenas agrupamentos espaciais das partes são extensos. Esses agrupamentos precisam de limites e esses limites são partes indivisíveis.
} 
solutamente impossível sempre conceber esses limites" (HUME, 2000, p. 33-34).Isso significa, segundo Hume, que as definições dos matemáticos confirmam que a extensão não é infinitamente divisível e que haja pontos matemáticos. Cabe a ele, entretanto, refutar as demonstrações da geometria que possuem um direcionamento contrário ao que estabeleceu em sua discussão sobre o espaço. De modo geral, sua estratégia será negar que as demonstrações da geometria se deem em base exata quando referidas a objetos mínimos como os pontos matemáticos. A igualdade só poderia ser estabelecida com base numa comparação envolvendo os pontos matemáticos. Uma geometria que os negue ou que pretenda não se formular a partir da noção aritmética de unidade só pode apresentar um critério aparente de comparação entre objetos, afirma Hume. Esse autor, em realidade, sustenta a posição de que a igualdade seja estabelecida apenas com base no aspecto global, impreciso, portanto. Não haveria um critério exato para diferenciar linha reta e curva ou um caminho mais curto e mais longo ou para estabelecer o que seja exatamente uma superfície plana. Sendo assim, as próprias demonstrações da geometria não conteriam a força e inquestionabilidade suficientes para serem provas inequívocas contra os pontos matemáticos. Hume está mostrando que a geometria se funda na percepção, tendo em vista que suas entidades básicas não são conceitos abstratos. Uma refutação analítica dos pontos matemáticos, portanto, não pode ser considerada suficiente para que se rejeite essa noção. A análise da experiência perceptiva aponta para a necessidade de que haja pontos matemáticos, destaca a filosofia humeana. Portanto, a geometria, cujas entidades básicas também dependem da percepção, deveria nos encaminhar para a 
confirmação da existência dos pontos matemáticos. ${ }^{10}$

Mas além do fato da extensão finita encontrar o limite da divisibilidade no ponto matemático, será preciso mostrar que o atomismo implica a dependência da ideia de espaço com relação às suas qualidades sensíveis, o que poderá ser realizado pela argumentação da necessidade de atribuição de cor e solidez aos pontos. Sobretudo, como era a própria estratégia de Berkeley, evidenciando a dependência da ideia de espaço com relação à sensação, e, nessa medida, a impossibilidade de sua abstração.

\section{A ORIGEM DA IDEIA DE ESPAÇO: GRÍTICA À ABSTRAÇÃO DA IDEIA DE ESPAÇO}

O próximo momento da análise da questão do espaço, no Tratado, aparecerá como consequência necessária da refutação de sua divisibilidade infinita e consistirá, acompanhando Berkeley, na negação da possibilidade de separação entre sua ideia e suas qualidades sensíveis. A crítica à abstração partirá da consideração de que não podendo haver divisão infinita, deve-se negar a hipótese da ideia de espaço ser composta de um número infinito de partes. Aceitandose, em contrapartida, que a ideia de espaço contém um número finito de partes, será preciso considerar que cada uma dessas partes deva ser preenchida por algo real e existente, ou seja, que não possa haver abstração de qualidades sensíveis, no caso, cor e tangibilidade.

É através da distinção entre impressões e ideias que a discussão acerca da origem da ideia de espaço é inicialmen-

\footnotetext{
${ }^{10}$ NEWMAN (1981, p. 21) sustenta que Hume está afirmando que a geometria prática é baseada num critério inexato de igualdade e que a geometria teórica só é possível com base numa aritmética exata do espaço, a qual pressupõe o conceito de ponto matemático.
} 
te enfocada no texto humeano. Por interposição do princípio da cópia, Hume conclui que a ideia de espaço deve estar fundada em alguma impressão. Ou seja, como a filosofia humeana estabelece que toda ideia simples é causada por uma impressão simples à qual se assemelha e que ideias complexas são composições de ideias simples, estabelece-se que a ideia de espaço deve ter sua origem em impressões simples. Como toda impressão é absolutamente clara e evidente, considerando-se de qual impressão deriva a ideia de espaço pode-se, segundo o autor, investigar sua natureza, sem que restem dúvidas na análise. Aplicando essa distinção ao caso da extensão, Hume chegará à conclusão de que a ideia de extensão "não é senão uma cópia desses pontos coloridos e da sua maneira de aparecer" (HUME, 2000, p. 27).

A ideia de um objeto extenso é, na visão exposta no Tratado, a ideia da composição de pontos coloridos, dispostos de um certo modo. É do objeto extenso que é recebida a ideia de extensão, da seguinte forma:

Suponhamos que em um objeto extenso, ou composição de pontos coloridos, do qual primeiro obtivemos a ideia de extensão, os pontos fossem da cor púrpura. Seguir-se-ia que em cada repetição dessa ideia não apenas colocaríamos os pontos na mesma ordem, mas também atribuiríamos a ela aquela cor precisa, com a qual estamos exclusivamente familiarizados. Mas após termos experiência de outras cores, como violeta, verde, vermelho, branco e preto, e todas as suas diferentes composições, e encontrando uma semelhança na disposição dos pontos coloridos dos quais são compostas, omitimos o tanto quanto possível as peculiaridades da cor e criamos uma ideia abstrata apenas com base na disposição dos pontos ou no seu modo em comum de aparecer (HUME, 2000, p. 28).

A discussão fundamental de Locke era a necessidade de diferenciar espaço e corpo. Tanto o espaço era considerado, de fato, diferente do corpo, que a existência de um es- 
paço absoluto mostrava que embora um corpo seja sempre espacial, o espaço existe sem o corpo, ambos se distinguindo. Hume negará essa possibilidade e, acompanhando Berkeley, verá problema na abstração do espaço, que é sempre relativo. Na discussão a respeito das ideias abstratas, no Tratado, sustenta-se que não possuímos ideias gerais, mas apenas ideias particulares que se tornam gerais quando anexadas a um termo geral. Toda concepção é sempre de ideias individuais, perfeitamente determinadas quantitativamente e qualitativamente. Esse seria o caso da ideia de espaço ou extensão. Mais especificamente, nesse caso, ocorreria algo semelhante ao que costuma ser chamado de distinção de razão, sobre a qual Hume discorre também por ocasião do seu comentário acerca da abstração. Propriamente, analisa o autor, a razão não faz distinção, na medida em que a mente não distingue aquilo que não é, de fato, separável; o procedimento é tão somente de comparação, da descoberta de uma relação. Para distinguir a figura de um corpo figurado, por exemplo, há um processo de observação de objetos semelhantes até que se possa por comparação separar a figura da cor. Com relação à ideia de extensão, poderíamos chegar ao modo de aparição dos pontos desconsiderando a sua cor, por uma comparação entre várias experiências e não por abstração. $\mathrm{O}$ modo de aparição de pontos determinados, separando-se a cor determinada, é a ideia geral de espaço, uma ideia que é geral apenas porque vinculada a um termo geral, sem deixar de ser em si mesma particular. Isso significará que há uma total dependência da percepção, não só na origem da ideia concebida, mas também quanto à sua natureza.

É interessante perceber que a filosofia humeana está apresentando uma concepção de espaço que o torna não 
diretamente sensorial, mas sim em alguma medida relacional. Hume não apenas se contrapõe à análise lockeana da ideia de espaço, segundo a qual esta é uma ideia simples distinta da ideia de corpo e extensão, porém derivada do mesmo ato de percepção. Ele acrescenta a tese de que a ideia de espaço equivale à maneira pela qual os pontos coloridos e tangíveis são dispostos. Evidentemente essa forma de conceber a ideia de espaço é bastante tributária de uma teoria da abstração que em grande medida é derivada da discussão berkleyana sobre o tema. Contudo, Hume não identifica a ideia de espaço com a impressão dos pontos coloridos e tangíveis. A impressão simples de que decorre a ideia complexa e abstrata de espaço é a de um ponto colorido e/ou tangível. Mas a ideia de espaço não é idêntica à ideia desses pontos e sim consiste no modo de disposição dos mesmos.

Evidentemente a forma como Hume aborda a ideia abstrata de espaço traz uma série de questões interpretativas, sobretudo quanto à coerência de sua exposição sobre o espaço e o tempo com o princípio da cópia, que orienta grande parte de sua filosofia. Não nos cabe neste artigo sustentar ou negar a consistência da exposição humeana ${ }^{11}$.

\footnotetext{
${ }^{11}$ FRASCA-SPADA (1998, p.158) afirma que a ideia de espaço em Hume é tanto atomística quanto relacional. Ademais consistiria em uma ideia ao mesmo tempo estritamente empírica e não totalmente sensorial. Aliar essas características, observa, apresenta uma série de complexidades. De modo geral, a autora defende que a ideia de espaço, ou seja a ideia do modo de aparição dos pontos visíveis e tangíveis que se apresentam a nós a partir dos objetos e distâncias à nossa volta, trata-se de uma contribuição da mente, uma ideia formada a partir de poderes e qualidades da mente com base em estímulos sensoriais (p. 56-83). Ademais, argumenta que, em Hume, uma impressão simples deve ser definida pela imediaticidade, portanto, como unidades emocionais e não propriamente visuais (p. 182), tese que de algum modo tenta "livrar" a filosofia humeana da alegação de inconsistência entre a sua análise do espaço e o seu princípio da cópia. COVENTRY (2010, p. 77-88) sintetiza uma série de críticas de comentadores quanto à ideia de espaço e tempo em Hume, sobretudo a de Kemp Smith, segundo o qual a "maneira pela qual os pontos coloridos e sólidos são dispostos" poderia ser objeto de intuição, mas não de sensação. A autora pretende apresentar uma resposta original à tese de inconsistência, propondo uma solução Cont.
} 
Entretanto, parece ser bastante pertinente destacar a originalidade de Hume neste ponto de discussão e perceber em que medida, relativizando ou não o princípio da cópia, a exposição da ideia de espaço ressalta a presença de uma atividade da mente (e não mera passividade) no estabelecimento de certas relações. Optamos neste artigo por investigar apenas a análise humeana do espaço, não a abordando conjuntamente com o tema do tempo em $\mathrm{Hu}-$ me, o qual, embora em grande medida envolvendo os mesmos argumentos empregados na discussão sobre o espaço, apresenta grande particularidade. Contudo, o modo como a filosofia humeana aborda a natureza da ideia de tempo é bastante ilustrativa neste momento daquilo em que consiste a originalidade da exposição humeana do espaço:

A ideia de tempo não é derivada de uma impressão particular misturada com outras e totalmente distinta delas, mas deriva da maneira como as impressões aparecem à mente, sem ser uma impressão adicional. Cinco notas tocadas em uma flauta nos dão a impressão e ideia de tempo, sem que o tempo seja uma sexta impressão que se apresente à audição ou a outro sentido. Tampouco ele é uma sexta impressão que a mente por reflexão encontra em si mesma. Esses cinco sons que aparecem dessa maneira particular não excitam nenhuma emoção na mente nem produzem afecção de qualquer tipo, que sendo observadas pela mente pudessem dar origem a uma nova ideia. Para que isso acontecesse seria preciso produzir uma nova ideia de reflexão. Mas a mente não pode, mesmo revirando mil vezes todas as suas ideias de sensação, extrair delas alguma nova ideia original, a menos que a natureza tenha aprimorado suas faculdades a ponto de sentir alguma nova impressão original a partir dessa contemplação. Ela apenas percebe a maneira pela qual os diferentes

alternativa a essa de Frasca-Spada, e também as de Falkenstein e Garret, os quais realizam uma discussão acerca da teoria das ideias abstratas aplicada à noção de espaço e tempo. Em síntese, Coventry afirma que a ideia abstrata de espaço, a ideia do modo de aparição de um conjunto de pontos visíveis e tangíveis, é uma ideia complexa derivada do modo de aparição de impressões complexas, as quais são redutíveis a pontos visíveis e tangíveis. Isso garantiria o respeito ao princípio da cópia e a significatividade da ideia de espaço preenchido. 
sons aparecem a ela e mais tarde pode considerar essa maneira, independente desses sons particulares, conjugando-a com outros objetos (HUME, 2000, p. 29).

Uma consequência importante das posições assumidas por Hume é a rejeição da ideia de vácuo ${ }^{12}$. A ideia abstrata de espaço é a ideia do modo como os pontos coloridos e tangíveis se dispõem, porém, pela natureza das ideias abstratas, tal como entendidas pela filosofia humeana, essa mesma ideia exige uma ideia particular concebível à qual o termo geral espaço será anexado. E essa ideia, por sua vez, precisa ser a composição de ideias simples que devem conservar a solidez e tangibilidade das impressões que a originam. Assim, ainda que a ideia abstrata de espaço seja a ideia da maneira como os pontos sólidos e tangíveis estão dispostos, e que possamos até mesmo problematizar a coerência dessa abordagem com o princípio da cópia, conforme expusemos acima, uma tal ideia gerada pela comparação não se equivale a ou permite a sustentação de uma ideia de uma extensão sem matéria. Uma total supressão de objetos visíveis e tangíveis ou seu posterior reaparecimento não nos forneceria a impressão de extensão sem matéria, portanto não geraria a ideia de vácuo.

O movimento e a escuridão, sozinhos ou acompanhados de objetos visíveis e tangíveis, afirma Hume, contudo, geram a ficção de que haja tal ideia, pela atuação de certos princípios da imaginação. Haveria uma semelhança entre

\footnotetext{
12 FRASCA-SPADA (1998, p. 158) argumenta ser a distância invisível e intangível uma versão radicalizada da noção de modo de aparição de pontos coloridos e sólidos que compõem os objetos que nos cercam. A distância imperceptível é um modo de aparição independente de quem percebe, é uma contribuição pura da mente, a partir da relação entre os objetos visíveis e tangíveis que se encontram nos extremos dessa distância imperceptível. COVENTRY (2010, p. 8788), por sua vez, defende simplesmente que Hume afirma não haver ideia de vácuo tendo em vista que não há impressões de pontos visíveis e tangíveis, os quais dariam origem só à ideia significativa de espaço preenchido, como vimos na interpretação da autora exposta na nota anterior.
} 
dois tipos de experiências, a saber, a de dois objetos visíveis e tangíveis distantes sem que haja alguma extensão entre os mesmo e a experiência de visibilidade e tangibilidade de duas extremidades entre as quais há pontos sólidos e tangíveis (portanto, uma extensão). Essa semelhança se daria tanto pela forma que esses objetos atingem os nossos sentidos, como pelo fato de que essas duas experiências geram a mesma sensação de movimento e porque nos dois casos a distância (preenchida ou não por extensão) diminui a força das qualidades como calor, frio, luz, atração, entre outras:

Essas relações entre os dois tipos de distância nos fornecem uma boa razão pela qual uma é tão frequentemente tomada pela outra e porque imaginamos ter uma ideia de extensão sem a ideia de algum objeto presente à vista ou ao tato. Porque podemos estabelecer como uma máxima geral nesta ciência da natureza humana que sempre que há uma relação estreita entre duas ideias a mente tende a confundi-las e usar uma pela outra em todos os seus discursos e raciocínios (HUME, 2000, p. 44).

Como segundo Hume é um princípio da imaginação confundir ideias ou atos mentais semelhantes, a mente, para equivaler as duas experiências, preencheria a experiência na qual há apenas dois objetos em extremidades sem extensão com a ideia de vácuo, um espaço sem matéria. Assim, quando após um movimento tocamos um objeto tendemos a criar a ficção de que entre o momento da ausência dessa sensação e a sua presença há um espaço que os preenche. $\mathrm{O}$ mesmo ocorreria quando há uma alternância da percepção de algo visível, a escuridão e uma nova percepção de algo visível. Dessa forma, Hume rejeita a tese de que o vácuo seja inteligível, sem com isso pretender refutar essa possibilidade quanto à existência real dos corpos e de suas qualidades. Trata-se apenas de apontar que não possuímos ideia inteligível de vácuo. Além disso, fica claro por meio 
dessa abordagem que a maneira de disposição dos pontos coloridos e sólidos, ainda que seja uma ideia abstrata distinta das ideias desses pontos, exige a presença aos sentidos dos mesmos, os quais devem, ao que parece, ser contínuos.

Suponhamos agora um homem suspenso no ar, sendo transportado por algum poder invisível. É evidente que ele não sente nada e nem recebe qualquer ideia de extensão ou qualquer outra derivada desse movimento invariável. Não recebe essa ideia mesmo se supusermos que movimenta suas pernas de um lado para o outro. Ele teria, nesse caso, uma certa sensação ou impressão, cujas partes sucessivas poderiam lhe fornecer a ideia de tempo. Mas certamente essas partes não estão dispostas de tal maneira que pudessem necessariamente originar a ideia de espaço ou extensão (HUME, 2000, p. 41).

Desse modo, Hume une as duas partes de seu sistema. Se a capacidade da mente é limitada não é possível haver divisão infinita da ideia de espaço. Deve haver ideias indivisíveis, as quais representam adequadamente seus objetos, na medida em que, pelo menos em imagem, nada é menor do que elas ${ }^{13}$. Considerando que os pontos coloridos que compõem a impressão da extensão devem preservar essa cor para formar a ideia de extensão, a teoria dos pontos matemáticos poderá superar as críticas de que os mesmos seriam não-entidades. Assim, por um lado, se os pontos matemáticos, quando dotados de cor e solidez, são possíveis, a indivisibilidade da extensão não pode ser refutada e, por outro lado, se eles mostram que a extensão não é algo distinto da percepção, é apenas o modo de disposição dos pontos coloridos. Mostrando que a ideia de extensão é de-

\footnotetext{
${ }^{13}$ MALHERBE (1992, P. 108) destaca que a solidariedade profunda entre as duas questões expostas por Hume tem em vista a defesa do princípio de análise que permeia toda a filosofia humeana. Uma divisão ao infinito do espaço e do tempo implicaria uma subversão da divisão de ideias complexas em ideias simples, decorrentes de impressões simples. A defesa de partes indivisíveis do espaço e do tempo, ademais, ressaltaria a tese empirista de que o ser é necessariamente atual.
} 
pendente dessas qualidades sensíveis, pode-se comprovar que o espaço é sempre relativo e, ademais, sempre particularizado, não podendo haver espaço abstrato, ou seja, uma ideia de extensão independente da sensação.

Abstract: In this article, one aims to analyze the Hume's discussion about the idea of space, presenting the debate about the rejection of the theory of infinite divisibility of extension and its defense of the perceptive atomism. Therefore, one starts from the context of analysis which Hume is inserted, that is, the debate between Locke and Berkeley regarding the abstraction of the extension. In this sense, the text attempts to point how Hume's debate concerning space results in sustaining the existence of mathematical points and to show how the thesis regarding the relational nature of space is Hume's form to seek the link between his perceptive atomism and abstractionism.

Keywords: Space; imagism; empiricism.

\section{REFERÊNGIAS}

BAXTER, Donalt L. M. Hume on Infinite Divisibility. History of Philosophy Quarterl, vol. 5, no. 2 (April) 1988, p. 133-140.

BERKELEY, George. Tratados sobre a visão: Um ensaio para uma nova teoria da visão e A teoria da visão confirmada e explicada. Trad. José Oscar de Almeida. Campinas: Editora da Unicamp, 2010.

BERKELEY, George. The Principles of Human Knowledge. Ed. Jonathan Dancy. Oxford: Oxford University Press, 1998.

COVENTRY, Angela M. Hume's System of Space and Time: Logical Analysis \& History of Philosophy, vol. 13 (January) 2010, p. 76-89. 
FRASCA-SPADA, Marina. Space and the self in Hume's Treatise. Cambridge: Cambridge University Press, 1998.

HUME, David. Treatise of Human Nature. Ed.David Fate Norton/ Mary Norton. Oxford: Oxford University Press, 2000 .

KEMP SMITH, N. The Philosophyof David Hume: a Critical Study of Its Origins and Central Doctrines. Londres: Macmillan, 1964.

LOCKE, John. An Essay Concerning Human Understanding. Nova York: Oxford University, 1975.

MALHERBE, Michel. La Philosophie Empiriste de David Hume. 3 ed. Paris: Vrin, 1992.

NEWMAN, Rosemary. Hume on Space and Geometry. Hume Studies, vol. VII, no. 1 (April) 1981, p. 1-31. 